\title{
BMJ
}

\section{Exposure to secondhand smoke and cognitive impairment in non-smokers: national cross sectional study with cotinine measurement}

\author{
David I Llewellyn, research associate, ${ }^{1}$ lain A Lang, research fellow, ${ }^{2}$ Kenneth M Langa, associate professor \\ of internal medicine, ${ }^{3,4,5}$ Felix Naughton, doctoral researcher, ${ }^{1}$ Fiona E Matthews, senior research scientist ${ }^{6}$
}

${ }^{1}$ Department of Public Health and Primary Care, University of Cambridge, Cambridge CB2 2SR ${ }^{2}$ Public Health and Epidemiology Group, Peninsula Medical School, Exeter

${ }^{3}$ Department of Internal Medicine University of Michigan, USA

${ }^{4}$ Veterans Affairs Center for

Practice Management and Outcomes Research, Michigan

${ }^{5}$ Institute for Social Research, University of Michigan

${ }^{6}$ MRC Biostatistics Unit, Institute of Public Health, Cambridge

Correspondence to: D J Llewellyn dl355@medschl.cam.ac.uk

Cite this as: $B M J$ 2009;338:b462 doi:10.1136/bmi.b462

\section{ABSTRACT}

Objective To examine the association between a biomarker of exposure to secondhand smoke (salivary cotinine concentration) and cognitive impairment. Design Cross sectional analysis of a national population based study.

Setting Stratified random sample of households throughout England.

Participants 4809 non-smoking adults aged 50 years or more from the 1998, 1999, and 2001 waves of the Health Survey for England who also participated in the 2002 wave of the English Longitudinal Study of Ageing and provided saliva samples for cotinine assay and a detailed smoking history. Main outcome measure Cognitive impairment as defined by the lowest $10 \%$ of scores on a battery of neuropsychological tests.

Results Participants who did not smoke, use nicotine products, or have salivary cotinine concentrations of 14.1 $\mathrm{ng} / \mathrm{ml}$ or more were divided into four equal size groups on the basis of cotinine concentrations. Compared with the lowest fourth of cotinine concentration $(0.0-0.1 \mathrm{ng} / \mathrm{ml})$ the odds ratios ( $95 \%$ confidence intervals) for cognitive impairment in the second $(0.2-0.3 \mathrm{ng} / \mathrm{ml})$, third $(0.4-0.7$ $\mathrm{ng} / \mathrm{ml})$, and highest fourths $(0.8-13.5 \mathrm{ng} / \mathrm{ml})$ were 1.08 (0.78 to 1.48), 1.13 (0.81 to 1.56 ), and 1.44 (1.07 to 1.94 ; $P$ for trend 0.02), after adjustment for a wide range of established risk factors for cognitive impairment. A similar pattern of associations was observed for never smokers and former smokers.

Conclusions Exposure to secondhand smoke may be associated with increased odds of cognitive impairment. Prospective nationally representative studies relating biomarkers of exposure to cognitive decline and risk of dementia are needed.

\section{INTRODUCTION}

Active smoking may be a risk factor for cognitive impairment and dementia, ${ }^{1}$ although it is not clear whether exposure to secondhand smoke is also a risk factor. The health effects of high levels of exposure to secondhand smoke may be close to those of active smoking, ${ }^{2}$ including an increased risk of lung cancer, diabetes, cardiovascular disease, hypertension, stroke, and death. ${ }^{3-9}$ As the risks associated with secondhand smoke have become clearer, an increasing number of governments have decided to legislate against smoking in public places. ${ }^{1011}$ Given the association between exposure to secondhand smoke and risk factors for cognitive impairment such as cardiovascular disease ${ }^{46}$ and stroke ${ }^{12}$ it is possible that such exposure may be a preventable risk factor for cognitive impairment. Previous findings also suggest that exposure to secondhand smoke may be associated with poor cognitive performance in children and adolescents. ${ }^{13-15}$

A preliminary analysis of 985 patients (728 women) aged 66-92 years from the Cardiovascular Health Study was carried out (T J Haight et al, 59th annual meeting of the American Academy of Neurology, Boston, 2007) and has been widely reported. ${ }^{16}$ Participants who had never smoked, had no history of cardiovascular disease or dementia, and self reported long term exposure to secondhand tobacco smoke (living with a smoker for 30 years or more) were about 30\% more likely to develop dementia over a six year period than those who were not exposed (relative hazard $1.3,95 \%$ confidence interval 0.95 to 1.82 ). This association did not, however, reach statistical significance when adjusted for age, sex, and education $(\mathrm{P}>0.05)$. In the same study, participants with subclinical carotid artery disease who lived with a smoker for 30 years or more were more likely to develop dementia (relative hazard 2.38, 1.23 to 4.63 ), suggesting a potential interaction between exposure to secondhand smoke and subclinical cardiovascular disease. Haight et al therefore hypothesised that exposure to secondhand smoke may be detrimental to cognitive health. Further research incorporating population representative samples while controlling for other factors that may be confounders is needed.

We examined the association between exposure to secondhand smoke and cognitive impairment in a large population based sample of non-smokers.

\section{METHODS}

Participants were from the 1998, 1999, and 2001 waves of the Health Survey for England ${ }^{17}$ who also participated in 
the 2002 wave of the English Longitudinal Study of Ageing. ${ }^{18}$ The Health Survey for England is a nationally representative multistage stratified random sample of the community dwelling English population. The core sample of the English Longitudinal Study of Ageing is limited to adults aged 50 years or more in 2002 and is drawn from the Health Survey for England sample by postcode sector (geographical area), stratified by health authority and proportion of households in non-manual socioeconomic groups. Of 11234 people who took part in both the Health Survey for England and the English Longitudinal Study of Ageing, 8893 were non-smokers at both time points. Cotinine measurements were obtained for most of the eligible non-smoking participants in the Health Survey for England waves 1998 (73\%) and 2001 (70\%), whereas only a randomly selected subsample of participants received a nurse visit in the 1999 wave and therefore provided a saliva sample $(8 \%)$. We restricted our analyses to the subsample of 5265 non-smoking participants whose salivary cotinine levels were measured. We excluded 22 participants with a self reported diagnosis of dementia, 205 participants who claimed to be non-smokers but used nicotine products or had salivary cotinine concentrations of $14.1 \mathrm{ng} / \mathrm{ml}$ or more (considered to be active smokers), ${ }^{19}$ and 229 who had missing values on one or more of the neuropsychological measures used to assess cognitive impairment. The remaining 4809 participants formed the sample for our analyses.

\section{Exposure to secondhand smoke}

We used levels of salivary cotinine $(\mathrm{ng} / \mathrm{ml})$ measured in the Health Survey for England as a biomarker for recent exposure to secondhand smoke (cotinine is a

Table 1 |Characteristics of non-smoking study population*. Values are numbers (percentages) unless stated otherwise

\begin{tabular}{|c|c|c|c|c|}
\hline Variables & $\begin{array}{l}\text { All participants } \\
(\mathrm{n}=4809)\end{array}$ & $\begin{array}{c}\text { Cognitively normal } \\
(n=4328)\end{array}$ & $\begin{array}{l}\text { Cognitively impaired } \\
(\mathrm{n}=481)\end{array}$ & $\begin{array}{l}P \text { for group } \\
\text { difference }\end{array}$ \\
\hline \multicolumn{5}{|l|}{ Exposure to secondhand smoke } \\
\hline $\begin{array}{l}\text { Median (interquartile range) } \dagger \text { salivary cotinine } \\
(\mathrm{ng} / \mathrm{ml})\end{array}$ & $0.3(0.1-0.7)$ & $0.3(0.1-0.7)$ & $0.4(0.1-1.0)$ & $<0.001$ \\
\hline \multicolumn{5}{|l|}{ Additional variables } \\
\hline Mean (SD) age (years) & $65.1(10.3)$ & $63.9(9.7)$ & $75.5(9.9)$ & $<0.001$ \\
\hline Women & $2557(53)$ & $2288(53)$ & $269(56)$ & 0.2 \\
\hline White ethnic origin & 4699 (98) & $4244(98)$ & $455(95)$ & $<0.001$ \\
\hline \multicolumn{5}{|l|}{ Highest educational qualification: } \\
\hline None & $1810(38)$ & $1451(34)$ & $359(75)$ & \multirow{3}{*}{$<0.001$} \\
\hline Intermediate & $1557(32)$ & $1475(34)$ & $82(17)$ & \\
\hline Degree or higher & $1442(30)$ & $1402(32)$ & $40(8)$ & \\
\hline Manual occupational class & $1822(38)$ & $1517(35)$ & $305(63)$ & $<0.001$ \\
\hline \multicolumn{5}{|l|}{ Health Survey for England wave: } \\
\hline 1998 & $2468(51)$ & $2201(51)$ & $267(56)$ & \multirow{3}{*}{0.07} \\
\hline 1999 & $124(3)$ & $109(3)$ & $15(3)$ & \\
\hline 2001 & $2217(46)$ & $2018(47)$ & $199(41)$ & \\
\hline $\begin{array}{l}\text { Median (interquartile range) net } \\
\text { non-housing wealth ( } £ \text { ) }\end{array}$ & $28000(4680-95000)$ & 31688 (5600-101 512) & $6400(1500-30504)$ & $<0.001$ \\
\hline \multicolumn{5}{|l|}{ Smoking history: } \\
\hline Never smokers & 2014 (42) & $1839(43)$ & $175(36)$ & \multirow{3}{*}{0.03} \\
\hline Former smokers (stopped «10 years ago) & 655 (14) & $582(14)$ & $73(15)$ & \\
\hline Former smokers (stopped $\geq 10$ years ago) & $2140(45)$ & 1907 (44) & $233(48)$ & \\
\hline Obesity (body mass index >29.9)† & $1137(24)$ & $1025(24)$ & $112(23)$ & 0.9 \\
\hline Physical inactivity & $497(10)$ & $377(9)$ & $120(25)$ & $<0.001$ \\
\hline \multicolumn{5}{|l|}{ Alcohol consumptiont: } \\
\hline $0 \mathrm{~g} /$ day & $481(10)$ & $372(9)$ & $109(23)$ & \multirow{3}{*}{$<0.001$} \\
\hline$>0-29.9 \mathrm{~g} /$ day & $3848(80)$ & $3507(81)$ & $341(70)$ & \\
\hline$\geq 30 \mathrm{~g} /$ day & $480(10)$ & $449(10)$ & $31(6)$ & \\
\hline Depressive symptoms (CESD >3) & $972(20)$ & $796(18)$ & $176(37)$ & $<0.001$ \\
\hline Diabetes & $320(7)$ & $259(6)$ & $61(13)$ & $<0.001$ \\
\hline Cardiovascular disease & $601(13)$ & $484(11)$ & $117(24)$ & $<0.001$ \\
\hline Stroke & $172(4)$ & $131(3)$ & $41(9)$ & $<0.001$ \\
\hline \multicolumn{5}{|l|}{ Hypertension: } \\
\hline Untreated & $475(10)$ & $436(10)$ & $39(8)$ & \multirow{2}{*}{0.001} \\
\hline Treated with antihypertensive drugs & $1354(28)$ & $1183(27)$ & $171(36)$ & \\
\hline
\end{tabular}

CESD is eight item version of Center for Epidemiological Studies depression scale. ${ }^{34} 35$

*205 participants who claimed to be non-smokers but used nicotine products or had salivary cotinine concentration $\geq 14.1 \mathrm{ng} / \mathrm{ml}$ were considered active smokers and were excluded. ${ }^{36} 22$ patients with a history of dementia were also excluded.

†Variables derived from Health Survey for England. All other variables derived from English Longitudinal Study of Ageing. 
metabolite of nicotine that has a half life of around 16-25 hours). ${ }^{20}$ Non-stimulated saliva samples were collected according to the Health Survey for England's protocol. ${ }^{17}$ Cotinine levels were analysed using a gas chromatograph machine (hp5890; Hewlett Packard, Palo Alto, CA, USA) with a rapid liquid chromatography technique by the Nicotine Laboratory at New Cross Hospital in London.

\section{Cognitive impairment}

Cognitive impairment was assessed using neuropsychological tests incorporated in the English Longitudinal Study of Ageing, which are described in detail elsewhere. ${ }^{21}$ Briefly, attention and processing speed were assessed using the letter cancellation task from the Medical Research Council National Study of Health and Development. ${ }^{22}$ Time orientation was assessed using questions from the mini-mental state examination. ${ }^{23}$ Immediate and delayed verbal memory were assessed using a 10-word learning task from the Health and Retirement Study. ${ }^{24}$ Prospective memory was assessed by asking participants to remember to write their initials in the top left corner of a piece of paper on a clipboard when it was handed to them later in the session (closely based on a task incorporated in the Medical Research Council Cognitive Function and Ageing Study), ${ }^{25}$ and by asking participants to remind the interviewer to record the time when he or she announced that the cognitive section was finished. Numeracy was assessed using questions relating to simple calculations based on everyday situations, and these items have also been incorporated in the Health and Retirement Study. ${ }^{24}$ The semantic verbal fluency task was taken from the Cambridge cognitive examination (CAMCOG), ${ }^{26}$ which examines how many unique animals people are able to name in one minute.

As the scoring of each individual test varied, we obtained a global cognitive function score by summing the standardised scores on each neuropsychological test. Such composite scores are regularly used because they integrate information from a variety of sources and thus provide a more stable representation of cognitive function than a single test. ${ }^{2728}$ We defined cognitive impairment as the lowest $10 \%$ of the distribution of cognitive performance. Such a population based cut-off point is a sensitive and specific marker of cognitive impairment ${ }^{29}$ and has been used in previous studies. $^{3031}$

\section{Statistical analysis}

We used multivariable logistic regression models to determine the cross sectional relation between exposure to secondhand smoke and cognitive impairment. We adjusted for key personal and known risk factors for cognitive impairment ${ }^{3233}$ : age, sex, ethnicity, education (highest educational qualification), manual occupational class, fourths of net non-housing wealth (measured in pounds sterling), smoking history (never smokers, former smokers who stopped smoking less than 10 years ago, former smokers who stopped smoking 10 years or more ago), obesity (body mass index >29.9), alcohol consumption (g/day), physical inactivity (participating in sport or physical activity less than once a month), and depressive symptoms (more than three symptoms on the eight item version of the Center for Epidemiological Studies depression scale). ${ }^{3435}$ Variables for adjustment were derived from the English Longitudinal Study of Ageing, with the exception of obesity and alcohol consumption, which were derived from the Health Survey for England.

In a secondary analysis we examined whether any observed association was mediated by a history of medical conditions thought to be associated with smoke inhalation (diabetes, cardiovascular disease, stroke, untreated and treated hypertension). ${ }^{3-912} \mathrm{We}$ analysed former smokers and never smokers separately and investigated whether the same pattern of associations was observed if cognition was operationalised as a continuous variable (global cognitive function) in multivariable linear regression models. In line with the preliminary analysis of Haight et al (59th annual meeting of the American Academy of Neurology) we also investigated the potential interaction between exposure to secondhand smoke and cardio-

Table 2 | Logistic regression models illustrating odds of cognitive impairment ( $95 \%$ confidence intervals) in 4809 non-smokers by salivary cotinine levels

\begin{tabular}{|c|c|c|c|}
\hline Variable & $\begin{array}{l}\text { Basic adjusted } \\
\text { model* }^{*}\end{array}$ & $\begin{array}{l}\text { Fully adjusted } \\
\text { model } †\end{array}$ & $\begin{array}{l}\text { Fully adjusted model } \\
\text { plus medical history }\end{array}$ \\
\hline \multicolumn{4}{|c|}{ Salivary cotinine fourths $(\mathrm{ng} / \mathrm{ml})$ : } \\
\hline Lowest (0.0-0.1) & Reference & Reference & Reference \\
\hline Second (0.2-0.3) & $1.13(0.83$ to 1.54$)$ & 1.08 (0.78 to 1.48$)$ & $1.08(0.79$ to 1.48$)$ \\
\hline Third (0.4-0.7) & $1.26(0.92$ to 1.72$)$ & $1.13(0.81$ to 1.56$)$ & $1.12(0.81$ to 1.56$)$ \\
\hline Highest (0.8-13.5) & 1.68 (1.27 to 2.22$)$ & $1.44(1.07$ to 1.94$)$ & $1.44(1.07$ to 1.93$)$ \\
\hline$P$ for trend & $<0.001$ & 0.02 & 0.02 \\
\hline
\end{tabular}

Population weights used to adjust for sampling design.

*Adjusted for age, sex, education, and testing interval.

†Adjusted for age, sex, education, testing interval, ethnicity, manual occupation, net wealth, smoking history, obesity, alcohol consumption, physical inactivity, and depressive symptoms.

$\ddagger$ Adjusted for age, sex, education, testing interval, ethnicity, manual occupation, net wealth, smoking history, obesity, alcohol consumption, physical inactivity, depressive symptoms, history of medical conditions (diabetes, cardiovascular disease, stroke, untreated hypertension, and hypertension treated with antihypertensive drugs). 
vascular disease. To take account of potential bias from non-response we used population weights from the English Longitudinal Study of Ageing to make the respondent sample more representative of the population. ${ }^{18}$ Non-response to the Health Survey for England and the English Longitudinal Study of Ageing both have the potential to make the respondent sample unrepresentative of the population. We therefore inverted the predicted probability of response for the responding households to provide the initial nonresponse weight. A further round of weighting was needed to adjust the initial household non-response weight to ensure that the weighted sample of responders closely matched the older English population. In addition, clusters and strata were used to allow for the original complex sample design of the Health Survey for England. We used Stata SE version 9.2 for all analyses (StataCorp, College Station, TX).

\section{RESULTS}

Table 1 shows the characteristics of those included in the analysis. Median salivary cotinine levels were low. The patterns of potential confounders observed were in keeping with the general population. The proportion of former smokers who stopped smoking more than 10 years ago was similar to those who never smoked. Most participants consumed alcohol, and about one in 10 were physically inactive. A large proportion of the study population was obese and had significant depressive symptoms or hypertension.

Non-smokers with valid cotinine measurements $(n=4809)$ were similar to the total eligible non-smoking sample from the English Longitudinal Study of Ageing $(\mathrm{n}=8061)$ for age $(65.1 v 65.7$ years $)$, sex (53.2\% v 55.3\% women), ethnic origin (97.7\% v 97.6\% white), education $(37.6 \%$ v $40.0 \%$ with no qualifications), and occupational class (37.9\% v 38.6\% manual).

Logistic regression was used to determine the relation between exposure to secondhand smoke and cognitive impairment in non-smokers (table 2). Adjustments were made for age, sex, education, and testing interval (basic adjusted models), and then additional covariables (fully adjusted models) were added (see table 2). Those with high levels of salivary cotinine
$(0.8-13.5 \mathrm{ng} / \mathrm{ml})$ were more likely to be cognitively impaired (odds ratio 1.44, 95\% confidence interval 1.07 to 1.94$)$ than those exposed to little or no secondhand smoke $(0.0-0.1 \mathrm{ng} / \mathrm{ml})$. Some evidence was found of a linear trend that might indicate a doseresponse relation $(\mathrm{P}=0.02)$. Additional adjustment for medical conditions such as cardiovascular disease had little effect.

Never smokers exposed to the highest levels of secondhand smoke (salivary cotinine concentrations $0.8-13.5 \mathrm{ng} / \mathrm{ml}$ ) were more likely to be cognitively impaired (odds ratio $1.70,1.03$ to 2.80 ) than those exposed to little or no secondhand smoke $(0.0-0.1 \mathrm{ng} / \mathrm{ml}$; table 3). Former smokers exposed to the highest levels of secondhand smoke also had increased odds of cognitive impairment $(1.32,0.92$ to 1.91$)$, although this association was weaker than that observed for never smokers.

The same pattern of associations was observed when cognitive function was analysed as a continuous variable across fourths of cotinine concentration for both basic models ( $\mathrm{P}$ for trend $<0.001$ ) and fully adjusted models ( $\mathrm{P}$ for trend 0.025$)$. The introduction of an interaction term to the fully adjusted logistic regression model indicated that there was no statistically significant interaction between history of cardiovascular disease and exposure to secondhand smoke $(\mathrm{P}>0.2)$.

\section{DISCUSSION}

High levels of salivary cotinine in non-smoking adults may be associated with increased odds of cognitive impairment. A similar pattern of results was observed for never and former smokers, and there was no interaction with a history of cardiovascular disease.

\section{Strengths and limitations}

This analysis is to our knowledge the first to examine the relation between exposure to secondhand smoke and cognitive impairment in a large heterogeneous population based sample. We controlled for a wide range of covariables that are potential confounders in cognitive research and incorporated an objective biomarker for exposure to secondhand smoke (salivary cotinine concentration). Comparisons with census

Table 3 | Logistic regression models illustrating odds of cognitive impairment (95\% confidence intervals) in former and never smokers by salivary cotinine levels

\begin{tabular}{|c|c|c|c|c|}
\hline \multirow[b]{2}{*}{ Variable } & \multicolumn{2}{|c|}{ Never smokers $(n=2014)$} & \multicolumn{2}{|c|}{ Former smokers $(n=2795)$} \\
\hline & Basic adjusted model* & Fully adjusted model† & Basic adjusted model* & Fully adjusted model $\dagger$ \\
\hline \multicolumn{5}{|c|}{$\begin{array}{l}\text { Salivary cotinine fourths } \\
(\mathrm{ng} / \mathrm{ml}) \text { : }\end{array}$} \\
\hline Lowest (0.0-0.1) & Reference & Reference & Reference & Reference \\
\hline Second (0.2-0.3) & $1.44(0.90$ to 2.31$)$ & $1.42(0.88$ to 2.31$)$ & 0.95 (0.63 to 1.45$)$ & $0.88(0.57$ to 1.34$)$ \\
\hline Third (0.4-0.7) & $1.26(0.77$ to 2.08$)$ & $1.16(0.68$ to 1.97$)$ & $1.26(0.85$ to 1.86$)$ & 1.11 (0.74 to 1.67$)$ \\
\hline Highest (0.8-13.5) & 1.75 (1.10 to 2.78$)$ & 1.70 (1.03 to 2.80$)$ & 1.62 (1.14 to 2.30$)$ & $1.32(0.92$ to 1.91$)$ \\
\hline $\mathrm{P}$ for trend & 0.03 & 0.08 & 0.005 & 0.1 \\
\hline
\end{tabular}

Population weights used to adjust for sampling design.

${ }^{*}$ Adjusted for age, sex, education, and testing interval.

†Adjusted for age, sex, education, testing interval, ethnicity, manual occupation, net wealth, smoking history, obesity, alcohol consumption, physical inactivity, and depressive symptoms. 
results show that the sample from the English Longitudinal Study of Ageing has a similar sociodemographic profile to the community living English population. ${ }^{18}$

Several methodological issues should be considered when interpreting our findings. The inclusion of former smokers is potentially problematic as historical exposure may be dominated by the former smoker's own previous smoking behaviours, and misclassification of current smoking status may be particularly likely in this group, leading to a residual confounding effect. We carried out analyses separately for former and never smokers, however, and the association between cotinine levels and cognitive impairment seemed stronger in never smokers. We also adjusted for smoking history as a potential confounder, including number of years since stopping smoking. Furthermore, we excluded 205 participants who claimed to be nonsmokers but used nicotine products or had salivary cotinine concentrations of $14.1 \mathrm{ng} / \mathrm{ml}$ or more as we considered them to be active smokers. ${ }^{19}$ Although cotinine is a valid, sensitive and specific biomarker for recent exposure to secondhand smoke, ${ }^{37}$ it does not necessarily reflect exposure over the long period during which cognitive impairment typically develops. However, cotinine levels have proved to be a useful marker of general levels of exposure to secondhand smoke. ${ }^{3738}$ We analysed a series of cross sectional data acquired over a mean of 2.6 years and did not find a causal relation. Although we controlled for a wide range of potential confounders the possibility of residual confounding remains. Non-smokers with valid cotinine measurements had a similar sociodemographic profile to the total non-smoking sample of the English Longitudinal Study of Ageing, and these variables were controlled for in the analyses, making systematic bias unlikely.

\section{Comparison with previous studies}

Haight et al (59th annual meeting of the American Academy of Neurology) reported a non-significant trend between self reported exposure to secondhand smoke and risk of incident dementia in never smokers

\section{WHAT IS ALREADY KNOWN ON THIS TOPIC}

Active smoking may be a risk factor for cognitive impairment, although it is not clear whether exposure to secondhand smoke is a risk factor

No previous study has examined the association between biomarkers of exposure to secondhand smoke and cognitive impairment

\section{WHAT THIS STUDY ADDS}

In a large diverse sample of non-smoking adults, high levels of cotinine were associated with increased odds of cognitive impairment

A similar pattern of results was observed for never and former smokers, and there was no interaction with a history of cardiovascular disease over a six year period. Their sample comprised almost exclusively women, whereas our sample was more heterogeneous. It is possible that their findings were not significant because of the reliance on self reported exposure. Self report measures of secondhand exposure have several important limitations-for example, living with a smoker captures less than half of the variation in cotinine concentration in non-smokers ${ }^{39}$ and does not take into account exposure in workplaces and public places. The association we observed between objectively measured cotinine levels and cognitive impairment is consistent with studies suggesting that active smoking may be a risk factor for cognitive impairment and dementia, ${ }^{1}$ and that exposure to secondhand smoke is associated with poor cognitive performance in children and adolescents. ${ }^{13-15}$

\section{Possible mechanisms}

Several mechanisms have been proposed to explain why exposure to secondhand smoke may increase the odds of cognitive impairment. Exposure to secondhand smoke is associated with an increased risk of cardiovascular disease, ${ }^{46}$ and cardiovascular disease may in turn be associated with an increased risk of cognitive impairment and dementia. ${ }^{4041}$ While additional adjustment for medical history made little difference to the fully adjusted model, and no interaction between cotinine levels and a history of cardiovascular disease was observed, it is possible that exposure to secondhand smoke may interact with subclinical cardiovascular disease, as observed by Haight et al (59th annual meeting of the American Academy of Neurology). Another study discovered that short term exposure to secondhand smoke adversely affects endothelial function in ways that immediately compromise the cardiovascular system. ${ }^{42}$ Dysfunctional endothelial cells contribute to vasoconstriction, atherogenesis, and thrombosis and may therefore compromise the blood supply to the brain. Exposure to secondhand smoke is also a risk factor for incident stroke, ${ }^{12}$ and differences in subclinical cerebrovascular disease may help to explain the noticeable individual differences in cognitive function observed during late adulthood. ${ }^{43}$ Reverse causality is also possible - for example, participants with cognitive impairment may metabolise nicotine differently from those without cognitive impairment.

\section{Conclusions}

Our results suggest that in a large diverse sample of non-smoking adults, high levels of cotinine may be associated with increased odds of cognitive impairment. Given the ongoing international policy debate on exposure to secondhand smoke, this is a topic of major public health significance. Prospective nationally representative studies of the association between biomarkers of exposure to secondhand smoke and cognitive decline and dementia are therefore warranted to assess the relation between secondhand smoke and cognitive health with greater precision. In the meantime, our results provide new evidence to 
suggest that exposure to secondhand smoke may be associated with increased odds of cognitive impairment.

We thank Fiona McDougall (University of Cambridge) and Robert Friedland (Case Western Reserve University) for their suggestions. Contributors: DJL conceived the study, acquired the data, did the statistical analysis, and is guarantor. All authors participated in the management, analysis, interpretation of data, and drafting of the manuscript. All have critically revised the manuscript for important intellectual content and seen and approved the final version.

Funding: The English Longitudinal Study of Ageing is funded by the US National Institute on Aging and a consortium of UK government departments. KML was supported by grants from the US National Institute on Aging (K08 AG019180 and R01 AG027010) and a Paul Beeson Physician Faculty Scholars in Aging Research award. IAL is an academic specialty registrar in public health supported by the National Health Service South-West Region Public Health Training scheme. FN is supported by a grant from Cancer Research UK [grant No C1345/A5809]. FEM is funded by the Medical Research Council [U.1052.00.013]. The sponsors played no part in the study design; the collection, analysis, and interpretation of data; the writing of the report; or the decision to submit the article for publication.

Competing interests: None declared.

Ethical approval: This study was approved by the Multicentre Research and Ethics Committee (MREC/01/2/91).

1 Anstey KJ, von Sanden C, Salim A, O’Kearney R. Smoking as a risk factor for dementia and cognitive decline: a meta-analysis of prospective studies. Am J Epidemiol 2007;166:367-78.

2 Barnoya J, Glantz SA. Cardiovascular effects of secondhand smoke: nearly as large as smoking. Circulation 2005;111:2684-98.

3 Woodward A, Laugesen M. How many deaths are caused by second hand cigarette smoke? Tob Control 2001;10:383-8.

4 Teo KK, Ounpuu S, Hawken S, Pandey MR, Valentin V, Hunt D, et al. Tobacco use and risk of myocardial infarction in 52 countries in the INTERHEART study: a case-control study. Lancet 2006;368:647-58.

5 Boffetta P. Human cancer from environmental pollutants: the epidemiological evidence. Mutat Res 2006;608:157-62.

6 Penn A, Chen LC, Snyder CA. Inhalation of steady-state sidestream smoke from one cigarette promotes arteriosclerotic plaque development. Circulation 1994;90:1363-7.

7 Iribarren C, Darbinian J, Klatsky AL, Friedman GD. Cohort study of exposure to environmental tobacco smoke and risk of first ischemic stroke and transient ischemic attack. Neuroepidemiology 2004;23:38-44.

8 Hayashino Y, Fukuhara S, Okamura T, Yamato H, Tanaka H, Tanaka T, et al. A prospective study of passive smoking and risk of diabetes in a cohort of workers: the High-Risk and Population Strategy for Occupational Health Promotion (HIPOP-OHP) study. Diabetes Care 2008;31:732-4

9 Felber Dietrich D, Schwartz J, Schindler C, Gaspoz JM, Barthelemy JC, Tschopp JM, et al. Effects of passive smoking on heart rate variability, heart rate and blood pressure: an observational study. Int J Epidemio 2007;36:834-40

10 Spinney L. Public smoking bans show signs of success in Europe. Lancet 2007;369:1507-8.

11 Koh HK, Joossens LX, Connolly GN. Making smoking history worldwide. N Engl J Med 2007;356:1496-8.

12 Bernal-Pacheco O, Roman GC. Environmental vascular risk factors: new perspectives for stroke prevention. J Neurol Sci 2007; 262:60-70.

13 Bauman KE, Flewelling RL, LaPrelle J. Parental cigarette smoking and cognitive performance of children. Health Psychol 1991;10:282-8.

14 Yolton K, Dietrich K, Auinger P, Lanphear BP, Hornung R. Exposure to environmental tobacco smoke and cognitive abilities among US children and adolescents. Environ Health Perspect 2005;113:98-103.

15 Rush D, Callahan KR. Exposure to passive cigarette smoking and child development. A critical review. Ann NY Acad Sci 1989;562:74-100.

16 Friedrich MJ. Researchers report new clues to dementia. JAMA 2007;298:161-3.

17 Erens B, Primatesta P, eds. The health survey for England 1998: cardiovascular disease 1998. London: Stationery Office, 1999.

18 Taylor R, Conway L, Calderwood L, Lessof C. Methodology. In: Marmot M, Banks J, Blundell R, Lessof C, Nazroo J, eds. Health, wealth and lifestyles of the older population in England: the 2002 English Longitudinal Study of Ageing. London: Institute of Fiscal Studies, 2003:357-74.

19 Jarvis MJ. Comparison of tests used to distinguish smokers from nonsmokers. Am J Public Health 1987;77:1435-8.
20 Wilcox RG, Hughes J, Roland J. Verification of smoking history in patients after infarction using urinary nicotine and cotinine measurements. BM/ 1979;2:1026-8.

21 Huppert FA, Gardener E, McWilliams B. Cognitive function. In: Banks J, Breeze E, Lessof C, Nazroo J, eds. Retirement, health and relationships of the older population in England: the 2004 English longitudinal study of ageing (wave 2). London: Institute for Fiscal Studies, 2006:217-42.

22 Richards M, Kuh D, Hardy R, Wadsworth M. Lifetime cognitive function and timing of the natural menopause. Neurology 1999;53:308-14.

23 Folstein MF, Folstein SE, McHugh PR. "Mini-mental state." A practica method for grading the cognitive state of patients for the clinician. J Psychiatr Res 1975;12:189-98.

24 Ofstedal M, Fisher G, Herzog A. Documentation of cognitive functioning measures in the Health and Retirement Study, 2005. HRS documentation report DR-006. Survey Research Center, University of Michigan: HRS Health Working Group.

25 Huppert FA, Johnson T, Nickson J. High prevalence of prospective memory impairment in the elderly and in early-stage dementia: findings from a population-based study. Appl Cogn Psychol 2000;14:S63-81.

26 Roth M, Tym E, Mountjoy CQ, Huppert FA, Hendrie H, Verma S, et al. CAMDEX. A standardised instrument for the diagnosis of mental disorder in the elderly with special reference to the early detection of dementia. Br J Psychiatry 1986;149:698-709.

27 Bennett DA, Wilson RS, Schneider JA, Evans DA, Beckett LA, Aggarwal NT, et al. Natural history of mild cognitive impairment in older persons. Neurology 2002;59:198-205.

28 Llewellyn DJ, Lang IA, Xie J, Huppert FA, Melzer D, Langa KM. Framingham stroke risk profile and poor cognitive function: a population-based study. BMC Neurol 2008;8:12.

29 Ganguli M, Belle S, Ratcliff G, Seaberg E, HuffFJ, von der Porten K, et al. Sensitivity and specificity for dementia of population-based criteria for cognitive impairment: the MoVIES project. / Gerontol 1993;48:M152-61.

30 Mulsant BH, Pollock BG, Kirshner M, Shen C, Dodge H, Ganguli M. Serum anticholinergic activity in a community-based sample of older adults: relationship with cognitive performance. Arch Gen Psychiatry 2003;60:198-203.

31 Weuve J, Kang JH, Manson JE, Breteler MM, Ware JH, Grodstein F. Physical activity, including walking, and cognitive function in older women. JAMA 2004;292:1454-61.

32 Hendrie HC, Albert MS, Butters MA, Gao S, Knopman DS, Launer LJ, et al. The NIH cognitive and emotional health project: report of the Critical Evaluation Study Committee. Alzheimer Demen 2006;2:12-32.

33 Patterson C, Feightner J, Garcia A, MacKnight C. General risk factors for dementia: A systematic evidence review. Alzheimers Dement 2007;3:341-7.

34 Cornoni-Huntley J, Ostfeld AM, Taylor JO, Wallace RB, Blazer D, Berkman LF, et al. Established populations for epidemiologic studies of the elderly: study design and methodology. Aging (Milano) 1993; 5:27-37

35 Fechner-Bates S, Coyne JC, Schwenk TL. The relationship of selfreported distress to depressive disorders and other psychopathology. J Consult Clin Psychol 1994;62:550-9.

36 Benowitz NL. Cotinine as a biomarker of environmental tobacco smoke exposure. Epidemiol Rev 1996;18:188-204.

37 Jarvis MJ, McNeill AD, Russell MA, West RJ, Bryant A, Feyerabend C. Passive smoking in adolescents: one-year stability of exposure in the home. Lancet 1987;1:1324-5.

38 Jarvis MJ, Feyerabend C, Bryant A, Hedges B, Primatesta P. Passive smoking in the home: plasma cotinine concentrations in nonsmokers with smoking partners. Tob Control 2001;10:368-74.

39 Breteler MM, Claus JJ, Grobbee DE, Hofman A. Cardiovascular diseas and distribution of cognitive function in elderly people: the Rotterdam Study. BMJ 1994;308:1604-8

40 Newman AB, Fitzpatrick AL, Lopez O, Jackson S, Lyketsos C, Jagust W, et al. Dementia and Alzheimer's disease incidence in relationship to cardiovascular disease in the Cardiovascular Health Study cohort. $J$ Am Geriatr Soc 2005;53:1101-7.

41 Otsuka R, Watanabe H, Hirata K, Tokai K, Muro T, Yoshiyama M, et al. Acute effects of passive smoking on the coronary circulation in healthy young adults. JAMA 2001;286:436-41.

42 Hachinski V. The 2005 Thomas Willis lecture: stroke and vascula cognitive impairment: a transdisciplinary, translational and transactional approach. Stroke 2007;38:1396.

43 Allwright S, Paul G, Greiner B, Mullally BJ, Pursell L, Kelly A, et al. Legislation for smoke-free workplaces and health of bar workers in Ireland: before and after study. BMJ 2005;331:1117.

Accepted: 13 November 2008 